\title{
Incurred sample reanalysis
}

In this issue of Bioanalysis we have focussed on incurred sample reanalysis, with the aim of providing some examples of incurred sample reanalysis failures and ensuing investigations, to provide a greater shared experience.

Welcome to this edition of Bioanalysis in which we focus on incurred sample reanalysis (ISR). In some sense, ISR sort of popped up out of nowhere in 2006. Although Canadian authorities had been pursuing ISR for some time, they had decided to forego this avenue by 2006 . The issue arose up at the AAPS conference in Crystal City, VA, USA. Scientists from industry, academia and government had gathered for the conference on bioanalytical method validation convened by AAPS and the US FDA [1]. The main focus of the conference had been updating issues with chromatographic assays, after some years of experience, and to discuss ligandbinding assays, which had begun to emerge as biological products started to gain approval for use in the marketplace. The FDA reported that as a consequence of ISR, significant methodological failures had been detected. Some of these failures had profound outcomes on the studies. This discussion triggered an energetic debate that raged to and fro for the next couple of years. Opponents had strongly argued that a properly validated method demonstrated the suitability of the assay. Proponents countered that ISR was the best means to assess whether the validated method, derived with spiked samples, truly reflected the behavior of patient samples, which by their nature were much more complicated.

In 2008, AAPS again hosted a meeting for scientists from industry, academia and government to discuss ISR. By this time, the issue had been debated extensively and, I think, a lot of clarity had been developed around the topic of ISR. The outcome of the meeting was the conference report that detailed the specifics regarding how to conduct an ISR study and the criteria to be used to assess the outcome [2].

However, even as the industry moved ahead with this practice, discontent continued among some of our colleagues. The debate, apparently, had not been settled. However, at various conferences across the continent, case studies of ISR failures were presented periodically in the following years. Apparently, as experience with ISR grew, methodological failures occurred, which seemed to 'validate' the use of this procedure. In fact, some of the opponents to ISR seemed to change their thinking about the topic.

In this issue of Bioanalysis, we have focused on ISR, with the aim of providing some examples of ISR failures and the ensuing investigations, to provide a greater shared experience. Furthermore, these authors also delve into the scientific thinking that is answering the next set of questions - what to do when ISR fails, should we still look into discrepancies if ISR passes, and so on. We also feature two editorials, one from Fabio Garofolo and one from Marian Kelly. Garofolo details some of the procedures his group follows to avoid ISR failures in their laboratory [3]. Kelly, extensively experienced with ligand-binding assays, describes in broad strokes the good science, using ISR as an example, that needs to prevail when evaluating small-or large-molecule assays [4]. As Kelly eloquently points out, we need to use good science and good judgment, because at the end of the exercise, these bioanalytical efforts are all about assuring patient safety. Enjoy!

\section{Financial \& competing interests disclosure}

The views expressed are those of the author and do not reflect official policy of the US FDA. No official endorsement by the FDA is intended or should be inferred. The author has no other relevant affliations or financial involvement with any organization or entity with a financial interest in or financial conflict with the subject matter or materials discussed in the manuscript apart from those disclosed.

No writing assistance was utilized in the production of this manuscript.

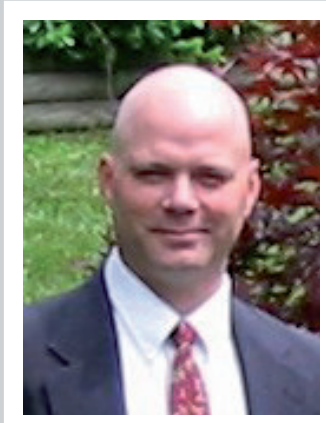

Brian Booth

US FDA, 10903 New Hampshire Avenue, BIdg 5I, Room 2186, MD 20993, USA

Tel.: +1 3017961508

E-mail: brian.booth@fda.hhs.gov 


\section{Bibliography}

1 Viswanathan CT, Bansal S, Booth B et al. Workshop/Conference Report - quantitative bioanalytical methods validation and implementation: best practices for chromatographic and ligand binding assays. Pharm. Res. 24(10), 1962-1973 (2007).

2 Fast D, Kelly M, Viswanathan CT. Workshop Report and Follow Up - AAPS workshop on current topics in GLP bioanalysis: assay reproducibility for incurred samples - implications of Crystal City recommendations. AAPS J. 11(2), 238-241 (2009).

3 Garofolo F, Bergeron A, Savoie N. How to manage having no ISR evaluation failures. Bioanalysis 3(9), 935-938 (2011).

4 Kelley M. Incurred sample reanalysis: it's just a matter of good scientific practice. Bioanalysis 3(9), 931-932 (2011). 